\title{
Habitat utilization and feeding ecology of small round goby in a shallow brackish lagoon
}

\author{
Christina Henseler ${ }^{1,2}$ D $\cdot$ Paul Kotterba $^{2} \cdot$ Erik Bonsdorff $^{1} \cdot$ Marie C. Nordström $^{1} \cdot$ Daniel Oesterwind $^{2}$
}

Received: 30 January 2020 / Revised: 1 July 2020 / Accepted: 13 July 2020 / Published online: 21 September 2020

(C) The Author(s) 2020

\begin{abstract}
We examined small-scale distribution and feeding ecology of a non-native fish species, round goby (Neogobius melanostomus (Pallas, 1814)), in different habitats of a coastal lagoon situated in the south-western Baltic Sea. First observations of round goby in this lagoon were reported in 2011, 3 years before the current study was conducted, and information on this species' basic ecology in different habitats is limited. We found that mainly juvenile round gobies are non-randomly distributed between habitats and that abundances potentially correlate positively with vegetation density and thus structural complexity of the environment. Abundances were highest in shallower, more densely vegetated habitats indicating that these areas might act as a refuge for small round gobies by possibly offering decreased predation risk and better feeding resources. Round goby diet composition was distinct for several length classes suggesting an ontogenetic diet shift concerning crustacean prey taxa between small ( $\leq 50 \mathrm{~mm}$ total length, feeding mainly on zooplankton) and medium individuals $(51-100 \mathrm{~mm}$, feeding mainly on benthic crustaceans) and another diet shift of increasing molluscivory with increasing body size across all length classes. Differences in round goby diet between habitats within the smallest length class might potentially be related to prey availability in the environment, which would point to an opportunistic feeding strategy. Here, we offer new insights into the basic ecology of round goby in littoral habitats, providing a better understanding of the ecological role of this invasive species in its non-native range, which might help to assess potential consequences for native fauna and ecosystems.
\end{abstract}

Keywords Baltic Sea $\cdot$ Biological invasion $\cdot$ Diet $\cdot$ Habitat types $\cdot$ Neogobius melanostomus

\section{Introduction}

The round goby (Neogobius melanostomus (Pallas, 1814)) originates from the Ponto-Caspian region and has colonized multiple water bodies as a non-native fish species, including the Great Lakes, the Baltic Sea and several European rivers like the Rhine. Thus, it occurs in various temperate freshwater

Communicated by C. Buschbaum

Electronic supplementary material The online version of this article (https://doi.org/10.1007/s12526-020-01098-0) contains supplementary material, which is available to authorized users.

Christina Henseler

christina.henseler@abo.fi

1 Environmental and Marine Biology, Åbo Akademi University, Artillerigatan 6, Biocity, 20520 Åbo, Finland

2 Thünen Institute of Baltic Sea Fisheries, Alter Hafen Süd 2, 18069 Rostock, Germany and brackish water systems and has become a dominant fish species in many of these invaded regions (Sapota and Skóra 2005; Kornis et al. 2012; Jůza et al. 2018). Concurrently, round gobies have become established in local food webs, feeding on a wide range of native organisms and serving as prey for several predatory fish species (e.g. cod and perch) and birds, such as cormorants and herons (Johnson et al. 2005; Almqvist et al. 2010; Hempel et al. 2016; Oesterwind et al. 2017; Herlevi et al. 2018). In their colonized range, round gobies can have severe impacts on the native fauna as they compete with native fish species for food resources and habitat, and prey on fish fry and juveniles (e.g. Janssen and Jude 2001; Steinhart et al. 2004; Houghton and Janssen 2015; Hirsch et al. 2016). Direct predation negatively affects macroinvertebrate communities leading to declines in abundance and biomass of certain prey species (e.g. Barton et al. 2005; Lederer et al. 2006; Kipp and Ricciardi 2012). These interactions with native species and the extensive distribution of round goby can result in cascading food web alterations in invaded ecosystems (Skabeikis et al. 2019) with possible 
consequences for ecosystem functioning in these regions. Therefore, a solid understanding of the basic ecology, such as habitat utilization and trophic role, of this fast spreading invasive species is essential in order to estimate potential impacts on native fauna and ecosystems.

Studies from several colonized areas have examined the distribution among habitats and diet of round goby. The species uses a variety of different habitats, but higher abundances are commonly associated with increased habitat complexity as provided by vegetated or rocky seabed (Ray and Corkum 2001; Sapota 2004; Cooper et al. 2007, 2009; Ramler and Keckeis 2020). Accordingly, round gobies show a preference for structurally more complex habitats, such as macrophytes and cobbles, over open sand areas in laboratory studies (Bauer et al. 2007; Duncan et al. 2011). Round gobies are mostly described as generalists with an opportunistic feeding strategy adapting their diet flexibly to prey availability in the environment (Borcherding et al. 2013; Brandner et al. 2013; Nurkse et al. 2016). They prey mainly on benthic macroinvertebrates including crustaceans (e.g. amphipods), insect larvae (mainly chironomids), molluses (such as bivalves and gastropods) and polychaetes. Fish are only consumed by larger individuals, whereas fish eggs and juveniles have a rather low contribution to round goby diet (e.g. Vašek et al. 2014; Ustups et al. 2016; Wiegleb et al. 2018; Hempel et al. 2019). However, round goby predation on eggs might generally be underestimated (Lutz et al. 2020). An ontogenetic diet shift has been reported for several water bodies with the dietary proportion of molluscs increasing with body size (Kipp et al. 2012; Brandner et al. 2013; Ustups et al. 2016; Hempel et al. 2019). The size, at which ontogenetic diet shifts of round goby occur, varies with study area, and slight differences in round goby diet concerning specific prey taxa exist, although the overall feeding ecology is rather similar among regions.

In the Baltic Sea, overall invasion rates of non-native species have consistently increased over the past decades with the first record of round goby dating back to 1990 from the Polish coast (Skóra and Stolarski 1993; Leppäkoski and Olenin 2000). Since then, the range of this species has expanded extensively in coastal areas (Kotta et al. 2016), emphasizing the importance of exploring its ecology and potential impacts on native ecosystems. Therefore, the aim of this study is to examine small-scale distribution and feeding ecology of round gobies in distinct littoral habitat types in a coastal brackish lagoon of the southern Baltic Sea, with a main focus on juveniles. Specifically, we (1) assess the abundance of round goby in different habitat types and (2) compare the diet between different size classes. Here, we present an overview of which prey items different round goby size classes feed on in the study area using stomach content data from late summer and autumn, right after the summer production peak. Additionally, we examine (3) how round goby diet might differ between habitats within one size class. Although first records of this species at the German coast of the Baltic Sea date back to 1998 (Winkler 2006), in our study area, round gobies were first caught in 2011 (Paul Kotterba, personal observation). Thus, we are exploring the basic ecology of this invasive species in a region, which has been invaded rather recently but where round goby has already established a viable population, which is why information on its ecology, especially the consideration of several habitat types, is quite scarce (Oesterwind et al. 2017; Wiegleb et al. 2018). This study will therefore contribute to broadening the knowledge on round goby in its invaded range, which is needed to more reliably predict potential impacts on ecosystems.

\section{Materials and methods}

\section{Study site and selected habitats}

Our study site "Greifswald Bay", a semi-enclosed inshore lagoon located in the south-western Baltic Sea at the German coast (Fig. 1), covers an area of $510 \mathrm{~km}^{2}$ with an average depth of $5.8 \mathrm{~m}$. Mean salinity ranges between 7 and 9 (Reinicke 1989; Stigge 1989). The grounds of shallow waters contain almost exclusively sand, besides mud, boulders and rocks (Reinicke 1989). The phytal zone reaches from the water surface to a maximum water depth of about $4 \mathrm{~m}$ consisting mainly of pondweed (Potamogetonaceae) and seagrass (Zostera marina), whereas bladderwrack (Fucus vesiculosus) is most abundant on stony substrates. Red algae, such as Furcellaria lumbricalis, are associated with rocks in slightly deeper areas between 3 and $6 \mathrm{~m}$ water depth (Geisel and Meßner 1989). The local fish fauna comprises both marine and freshwater species such as herring (Clupea harengus), flounder (Platichthys flesus), pike (Esox lucius), pikeperch (Sander lucioperca) and perch (Perca fluviatilis) (Winkler 1989). First records of round goby in Greifswald Bay were reported in 2011 (Paul Kotterba, personal observation).

Round gobies were sampled in different pre-defined habitat types at "Gahlkow", situated in the southern part of Greifswald Bay (Fig. 1). The littoral zone in this area is characterized by a depth-stratified succession of different submerged aquatic vegetation (SAV) communities, which represents a common structure of local soft bottom shore zones in the bay. Based on earlier studies (Moll et al. 2018) and footage recorded by an underwater camera, sampling areas were selected and habitats characterized according to the general phytal zonation in the bay described by Geisel and Meßner (1989) following the natural depth gradient. The "Potamogeton-zone" ( $P Z$, pondweed zone) in our study ranged from 1 to $2 \mathrm{~m}$ water depth, where the seafloor is densely covered with different macrophyte species including Stuckenia pectinata and Z. marina (Kanstinger et al. 2018). 
Fig. 1 Location of Greifswald Bay (GB) and the round goby sampling site at Gahlkow (GK), marked with a black asterisk. The blue asterisk in the inset map marks the location of Greifswald Bay at the German coast in the south-western Baltic Sea

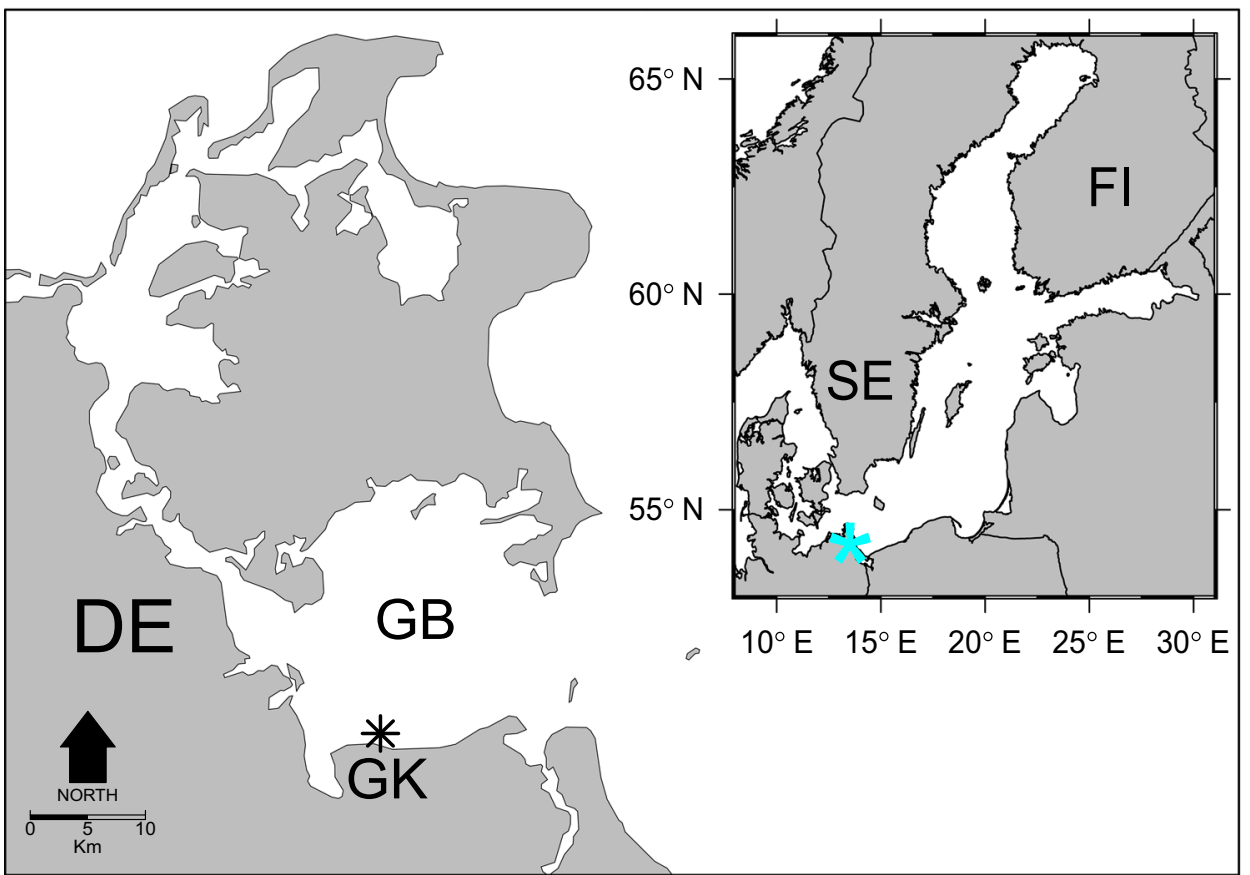

The "Zostera-zone" ( $Z Z$, seagrass zone) between 3 and $4 \mathrm{~m}$ depth was characterized by less dense and more patchily distributed SAV consisting mostly of $Z$. marina. No vegetation occurred in the "sub-phytal zone" (SZ) between 5 and $7 \mathrm{~m}$ depth, and the sediment consisted of bare sand. In all habitat types, the main bottom substrate was sand.

\section{Round goby sampling}

Round goby samples were taken with a 2 m-wide beam trawl (mesh size, $5 \mathrm{~mm}$ ), which was towed over the seafloor with constant speed ( 2 knots). Hauls in the habitats were conducted with a towing time between 2 and $11 \mathrm{~min}$, depending on SAV density (Supplementary Table S1). The position of the boat was recorded each second with a handheld global positioning system resulting in continuously recorded tracks for each haul. Track distance and beam trawl width were used to calculate the respective sampling area for each haul. Round gobies were sampled in late summer and autumn 2014 with respectively one sampling in August, October and November during daytime (between 10 am and 2 pm, local time). In August, one haul was conducted in the $P Z$ and two additional hauls in the transition-zone between the $P Z$ and $Z Z$ in 2 to $3 \mathrm{~m}$ water depth ("Potamogeton/Zostera-transition-zone" = PZTZ). In October and November, three replicate hauls were conducted in each habitat type $(P Z, Z Z, S Z)$ resulting in nine hauls in total for each month. The sampling procedure in August deviated slightly from the one in October and November because it was conducted as a pilot sampling, after which the methodology was improved and adjusted to local conditions, i.e. sampling in specific habitats and reduction of hauling duration (cf.
Supplementary Table S1). Therefore, data from August was only included in the diet analysis, but not in the comparison of round goby abundance between habitats. Round goby samples were frozen directly on board and stored at $-30^{\circ} \mathrm{C}$ until further processing.

\section{Laboratory and stomach content analysis}

For the analysis of round goby diet composition, stomach content analyses were conducted. Sampled round gobies were counted, and total length (TL) and wet weight were recorded to the nearest $\mathrm{mm}$ and $0.01 \mathrm{~g}$, respectively. For the stomach content analyses, gobies were assigned to three length classes $(\mathrm{LC}): \leq 50 \mathrm{~mm}\left(\mathrm{LC}_{1}\right), 51-100 \mathrm{~mm}\left(\mathrm{LC}_{2}\right)$ and $101-150 \mathrm{~mm}$ $\left(\mathrm{LC}_{3}\right)$. Stomach contents were examined from at least ten gobies per LC for each haul in August, October and November. Round gobies were dissected ventrally, and the stomach was separated from the remaining digestive tract. Stomach contents were examined under a binocular microscope and prey items determined to the lowest possible taxonomic level. The presence/absence of prey organism taxa was noted for each stomach. The data on round goby diet has been used for a merely descriptive purpose in Oesterwind et al. (2017) before.

\section{Statistical analysis}

All statistical analyses were carried out in the open source software R, version 3.6.1 (R Core Team 2019). To test whether round goby abundance differed between habitat types, abundances were compared statistically between habitats for 
October and November, i.e. these months when the same habitats had been sampled $(P Z, Z Z, S Z)$, by means of Generalized Linear Models (GLM) using Type II Sum of Squares with the car package (Fox and Weisberg 2011). GLMs were executed with round goby count data as the response variable using a quasipoisson distribution and a log-link function for October data and a negative binomial distribution (MASS package; Venables and Ripley 2002) and a squared-link function for November data. In both models, an offset with the respective sampling area of each haul was included. To ensure that GLMs met assumptions regarding data normality and homoscedasticity, residuals were plotted against fitted values. To assess how single habitats differed from each other concerning round goby abundance, post-hoc tests were conducted using the Bonferroni correction.

For the comparison of round goby diet between length classes, data from the three sampling months (August, October and November) were pooled across all habitats to obtain a sufficient sample size. Therefore, the comparison among length classes gives an overview of what gobies of different sizes feed on in general in the study area irrespective of sampling month and without taking into account a possible variability in prey availability and round goby diet (for diet composition separated into length classes for each month, cf. Supplementary Fig. S1). To test whether diet composition differed between the three length classes, permutational multivariate ANOVA (PERMANOVA) with 9999 permutations was used on presence/absence data. A permutational test of multivariate dispersion (PERMDISP) was conducted prior to the PERMANOVA, to test whether the within-group spread of the observations to their group centroid (i.e. multivariate dispersions) was equal between length classes. To achieve homogeneity of multivariate dispersions, $\mathrm{LC}_{3}$ had to be excluded from the analysis. Hence, PERMANOVA and the subsequent analysis were only applied for the comparison between $\mathrm{LC}_{1}$ and $\mathrm{LC}_{2}$. A similarity percentage (SIMPER) analysis was conducted to assess the dissimilarity between $\mathrm{LC}_{1}$ and $\mathrm{LC}_{2}$ based on round goby diet composition and to identify the contribution of prey items to this diet difference. To test whether diet composition of round gobies differed between habitat types within one length class $\left(\mathrm{LC}_{1}\right)$, PERMDISP and PERMANOVA were applied for October and November data separately. Only $\mathrm{LC}_{1}$ was considered in this analysis to avoid length class-based differences in diet to overshadow habitat effects, and because only gobies from this smallest LC were present in all habitat types (cf. Supplementary Table S1). The binomial dissimilarity index was used for the above described multivariate analyses (PERMDISP, PERMANOVA), as it can handle binary data and different sample sizes between groups. For the multivariate analyses, the vegan package (Oksanen et al. 2018) was used. Maps were generated in $\mathrm{R}$ using the following packages: GISTools, rgdal, raster and oceanmap (Brunsdon and Chen 2014; Bivand et al. 2017; Hijmans 2017; Bauer 2018).

\section{Results}

Besides round gobies, eleven other fish species were present in the beam trawl samples from August, October and November (Supplementary Table S2). Two pipefish species (Nerophis ophidion and Syngnathus typhle) represented the most abundant fish group (Supplementary Fig. S2) followed by native gobies, Pomatoschistus spp., round goby and the three-spined stickleback Gasterosteus aculeatus. Other fish species had a comparatively low occurrence in the samples.

\section{Habitat utilization of round goby}

Round goby abundances were compared between habitats for October and November, since all three habitat types were sampled during these months, but not in August. In total, 124 round gobies were caught in October and 273 individuals in November across all sampled habitats (Supplementary Table S1). Total length ranged between 16 and $129 \mathrm{~mm}$ for October and November with the majority of gobies $(95.97 \%)$ assigned to $\mathrm{LC}_{1}(\leq 50 \mathrm{~mm})$. Additionally, $3.78 \%$ were grouped into $\mathrm{LC}_{2}(51-100 \mathrm{~mm})$ and $0.25 \%$ into $\mathrm{LC}_{3}(101-$ $150 \mathrm{~mm}$ ). Mean total length ( \pm standard deviation) in October was $35.0 \pm 12.9 \mathrm{~mm}$ and $37.3 \pm 6.9 \mathrm{~mm}$ in November. Round goby abundance differed significantly between habitats for October based on GLM results $\left(p=0.027, F_{2,6}=7.03\right.$; Fig. 2a). However, post-hoc tests did not show any significant differences between habitats. Nevertheless, round goby abundance was clearly higher in the $P Z$ (mean abundance \pm standard deviation $=6.82 \pm 0.71 n / 100 \mathrm{~m}^{2}$ ) compared with the $Z Z$ $\left(0.62 \pm 1.07 n / 100 \mathrm{~m}^{2}\right)$ and $S Z\left(1.31 \pm 1.70 n / 100 \mathrm{~m}^{2}\right)$, and post-hoc results were rather close to being significant for the

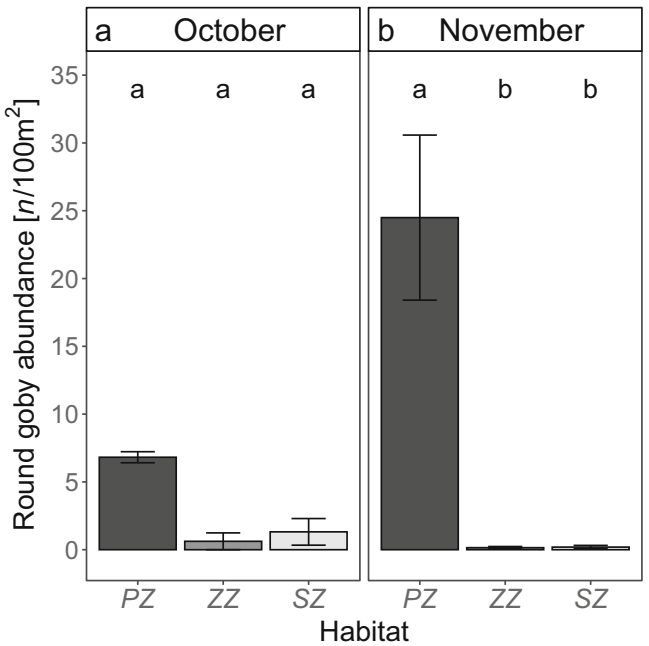

Fig. 2 Mean round goby abundance $\left(n / 100 \mathrm{~m}^{2}\right)$ and standard error in a October and $\mathbf{b}$ November in the different habitats: PZ Potamogeton-zone, $Z Z$ Zostera-zone and $S Z$ sub-phytal zone. Letters indicate significant differences between habitats based on post-hoc comparisons. Habitats with the same letter are not significantly different. The significance level was set to 0.05 
comparison of the $P Z$ and $Z Z(p=0.080)$. GLMs revealed that abundances differed significantly between habitats for November $\left(p<0.001, F_{2,6}=75.78 ;\right.$ Fig. $\left.2 b\right)$ with higher goby abundances in the $P Z\left(24.49 \pm 10.54 \mathrm{n} / 100 \mathrm{~m}^{2}\right)$ than in the $Z Z$ $\left(0.15 \pm 0.15 \mathrm{n} / 100 \mathrm{~m}^{2}\right)$ and $S Z\left(0.19 \pm 0.22 \mathrm{n} / 100 \mathrm{~m}^{2}\right)$, which was confirmed by post-hoc comparisons.

\section{Diet composition in different length classes}

In total, 163 round goby stomachs were examined from August, October and November samples. Thereof 26 stomachs only contained mucus and sand, and another five stomachs contained non-identifiable prey items, resulting in 132 round goby stomachs considered in the diet analysis. The diet composition showed distinct differences between the three length classes. While round gobies in $\mathrm{LC}_{1}$ and $\mathrm{LC}_{2}$ predominantly fed on arthropods (89\% and $70 \%$ of gobies per length class respectively; Fig. $3 a, b)$, the percentage of polychaetes and molluscs increased in the diet of $\mathrm{LC}_{3}$ with $60 \%$ of gobies consuming arthropods and molluscs and $80 \%$ feeding on polychaetes (Fig. 3c). The diet composition based on the three main taxa (displayed in Fig. 3a-c) divided into lower taxonomic groups (Fig. 3d-f) differed significantly between $\mathrm{LC}_{1}$ and $\mathrm{LC}_{2}$ (PERMANOVA: $p<0.001, F_{1}=20.10$ ). The between-group dissimilarity between these length classes was $86 \%$ based on SIMPER results. Prey groups contributing most to this difference were copepods, ostracods, gastropods and isopods, which together explained $57 \%$ of the between-length class dissimilarity (for SIMPER results, cf. Supplementary Table S3). In $\mathrm{LC}_{1}$, respectively $52 \%$ of round gobies consumed ostracods and copepods, whereas individuals in $\mathrm{LC}_{2}$ fed increasingly on gastropods (30\% of gobies) and isopods $(41 \%$ of gobies; Fig. 3d, e). Additionally, $17 \%$ of $\mathrm{LC}_{1}$ gobies consumed cladocerans, which were not present in the diet of $\mathrm{LC}_{2}$. However, $33 \%$ of round gobies in $\mathrm{LC}_{2}$ fed on amphipods. Keeping in mind that the sample size in $\mathrm{LC}_{3}$ was
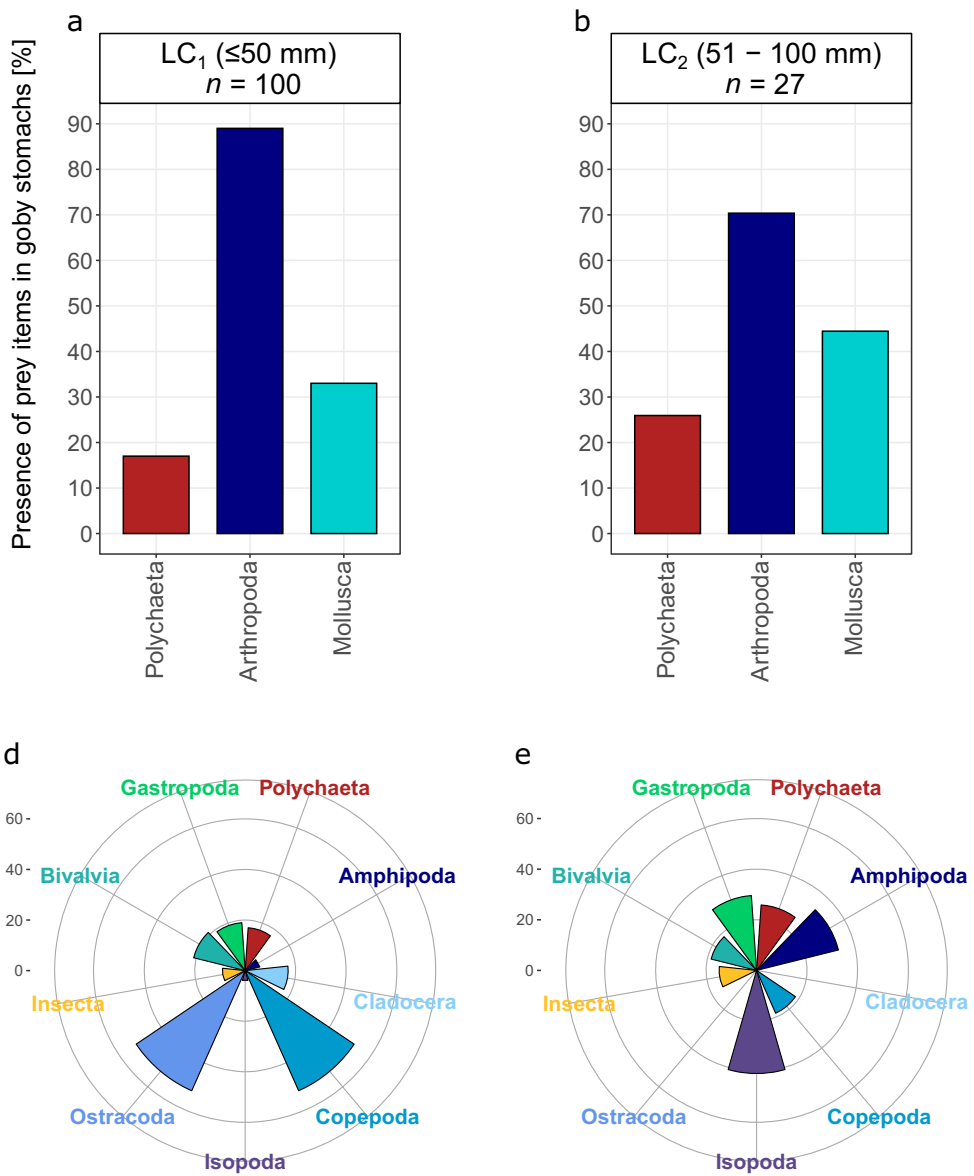
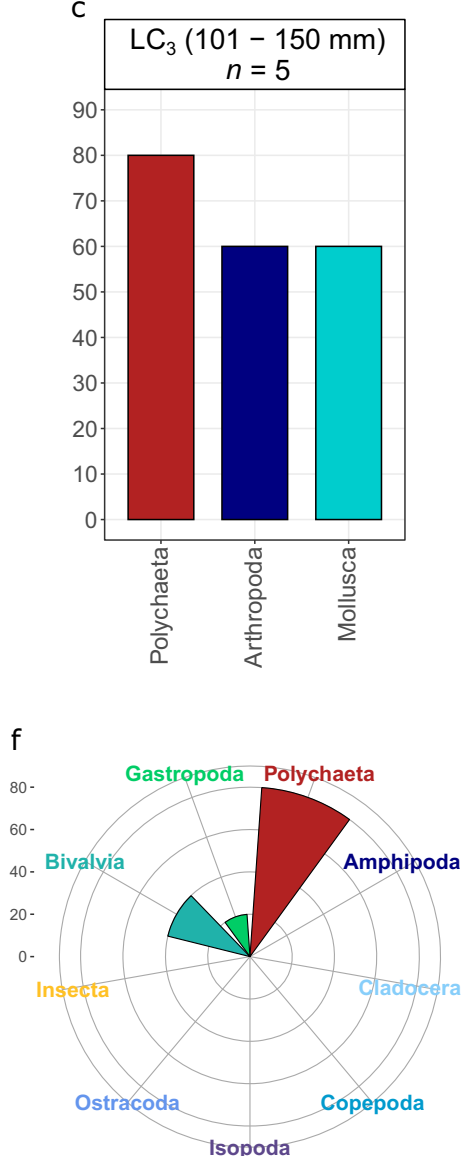

Fig. 3 Diet composition of round gobies displaying the three main prey taxa (upper row) and main taxa divided into lower taxonomic groups (lower row). Diet composition is shown as percentage (\%) of round gobies that had consumed the respective prey item in length class $\mathrm{LC}_{1}$ ( $\leq 50 \mathrm{~mm} \mathrm{TL}$ ) (a and d), LC 2 (51-100 mm TL) (b and e) and $\mathrm{LC}_{3}(101-$ $150 \mathrm{~mm} \mathrm{TL}$ ) (c and $\mathbf{f}$ ). $n$ refers to the number of round goby stomachs examined in the respective LC. All round gobies with non-empty stomachs examined from August, October and November are considered. Note the different scale of the $y$-axis in (f). No arthropod prey items are displayed in (f), as they could not be assigned to any of the lower taxonomic groups, i.e. arthropod prey items were unidentifiable 
rather low $(n=5)$, which is why no statistics could be applied, the diet composition in $\mathrm{LC}_{3}$ showed differences to the diet of the smaller length classes. In $\mathrm{LC}_{3}$, a higher percentage of gobies consumed polychaetes $(80 \%)$ and bivalves (40\%; Fig. $3 \mathrm{c}$ and $\mathrm{f}$ ).

\section{Diet composition in different habitat types}

The diet composition of round gobies was compared between habitat types for October and November in $\mathrm{LC}_{1}$. Due to nonhomogeneity of multivariate dispersions between habitats for October data, PERMANOVA could not be applied. For November data, PERMANOVA did not show a difference in diet composition between habitats $\left(p=0.066, F_{2}=2.39\right.$ ), although results were quite close to being significant at a 0.05 significance level. However, based on qualitative observations, diet composition showed certain differences between habitat types in $\mathrm{LC}_{1}$, both in October and November (Fig. 4). Round goby diet was more diverse in the $P Z$ comprising nine and six prey taxa in October and November, respectively, whereas a maximum of four different prey items was consumed in the $Z Z$ and $S Z$. Correspondingly, certain taxa, such as amphipods and isopods, were only present in round goby diet in the PZ. $4 \%$ of individuals fed on amphipods in October and $8 \%$ in November, while $11 \%$ of gobies consumed isopods in October (Fig. $4 \mathrm{a}$ and d).

\section{Discussion}

In this study, we provide information on small-scale distribution and feeding ecology of a non-native fish species, round goby, in different habitats of a recently colonized shallow lagoon in the south-western Baltic Sea. This knowledge is essential for a better understanding of the ecological role of this invasive species in the littoral zone of colonized areas. We found higher round goby abundances in the shallower vegetated habitat, and the diet composition was distinct for different round goby size classes, additionally displaying certain differences between habitat types. Our findings could support the evaluation of how native fauna and thus ecosystems might be affected by the invasion and rapid expansion of round goby and therefore assist in management actions.

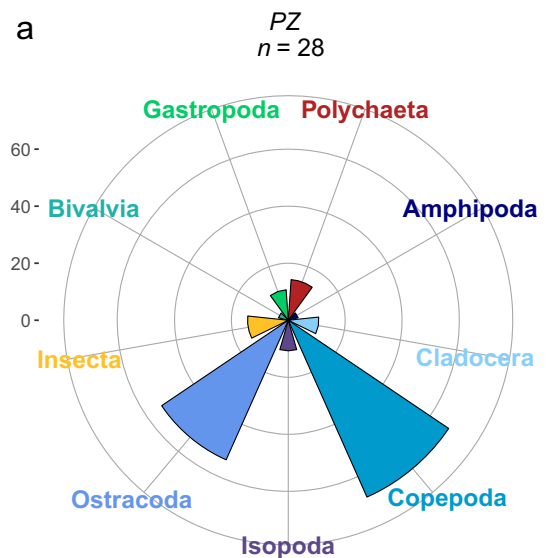

d

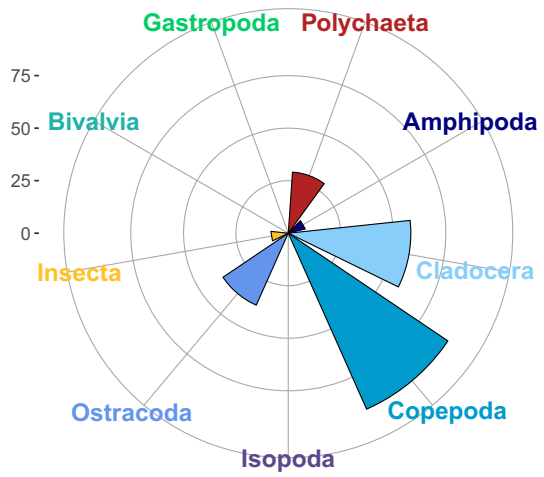

b

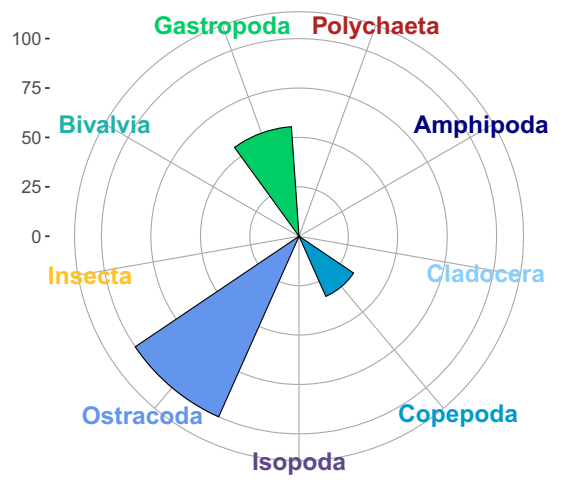

e

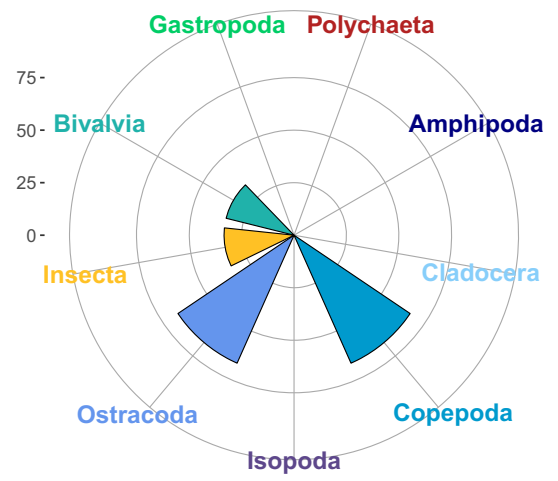

c

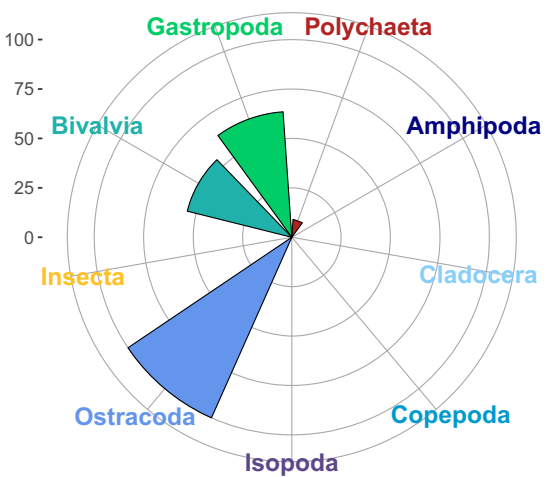

f

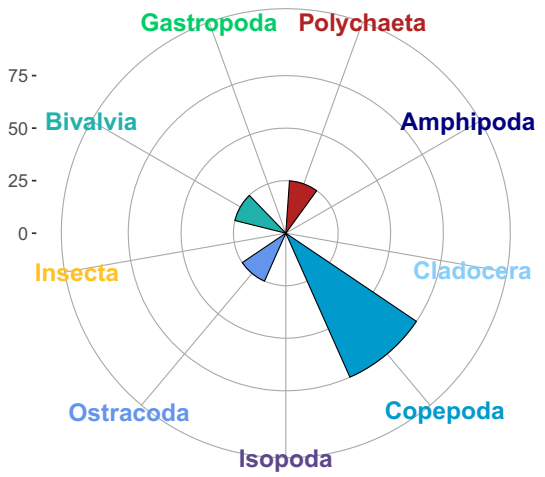

Fig. 4 Diet composition with main taxa divided into lower taxonomic groups, shown as percentage (\%) of round gobies from length class $\mathrm{LC}_{1}$ $(\leq 50 \mathrm{~mm} \mathrm{TL})$ that had consumed the respective prey item, in the Potamogeton-zone (PZ) (a and d), the Zostera-zone ( $Z Z)$ (b and $\mathbf{e})$ and the sub-phytal zone (SZ) (c and $\mathbf{f}$ ) in October (top row) and November (bottom row). $n$ refers to the number of round goby stomachs examined in the respective habitat per month. Note the different scale of the $y$-axes 


\section{Habitat use of round goby}

Both in October and November, round gobies were more abundant in the $P Z$ compared with the other two habitats (cf. Fig. 2). Whereas GLMs showed significant differences in round goby abundance between habitats for both months, post-hoc tests indicated significant differences only for November. Non-significant post-hoc results for October data might be caused by the relatively low replicate number in general and a comparatively high number of gobies in one of the three replicate hauls in the $S Z$ (cf. Supplementary Table S1), which might possibly not have been representative for this habitat type due to, e.g. comparatively dense vegetation. Nonetheless, abundances were clearly higher in the $P Z$ $\left(6.82 \pm 0.71 \mathrm{n} / 100 \mathrm{~m}^{2}\right)$ compared with the other two habitats $\left(Z Z, 0.62 \pm 1.07 n / 100 \mathrm{~m}^{2} ; S Z, 1.31 \pm 1.70 \mathrm{n} / 100 \mathrm{~m}^{2}\right)$ based on qualitative observations in October (Fig. 2). Since the shallow $P Z$ was characterized by dense vegetation, it most likely represented the structurally most complex habitat compared with the less vegetated $Z Z$ and the bare sand area in the $S Z$. Additionally, round gobies sampled in October and November were comparatively small (mean total length \pm standard deviation, $36.6 \pm 9.2 \mathrm{~mm}$ ) indicating that shallower, more structured areas with dense submerged aquatic vegetation (SAV) represent an important habitat for juvenile specimen at the study site. This is in accordance with general habitat preferences of round gobies in laboratory experiments, in which more complex cobble and macrophyte habitats were favoured over less complex open sand areas (Bauer et al. 2007; Duncan et al. 2011). Similarly, round gobies were more abundant in SAV and rock habitats than in water lily and bare sediment habitats in the Great Lakes (Ray and Corkum 2001; Cooper et al. 2007, 2009). In its native range, the PontoCaspian region, this species utilizes shallow hard substrates (rocks, gravel, mussel beds), but also seagrass meadows (Svetovidov 1964; Bogutskaya et al. 2004). However, Moran and Simon (2013) documented the occurrence of smaller round gobies in less complex gravel habitats, while larger individuals were associated with structurally more complex areas, suggesting that habitat type alone might not be the sole factor explaining the distribution of this species (Coulter et al. 2015). The presence of small, mainly juvenile, round gobies at the study site might be related to its relatively young invasion history as small round gobies have been linked to more recently colonized sites and larger individuals to originally invaded areas (Ray and Corkum 2001). Round gobies at our study site reached a total length of up to $14 \mathrm{~cm}$ and therefore seemed to be aged between 0 and 5 years according to Florin et al. (2018), which would be in accordance with their presumptive young invasion history in Greifswald Bay (study performed 3 years after first observation).

Regardless of whether round gobies always reach higher abundances in more complex vegetated habitats, several benefits are associated with using this type of habitat. Densely vegetated habitats generally offer lower predation risk than open areas, most likely due to a higher availability of hiding places and reduced conspicuousness of prey fish (e.g. Savino and Stein 1982; Chacin and Stallings 2016). Indeed, predation on round gobies is lower in more sheltered habitats, and especially small individuals are exposed to high predation pressure in open habitats (Belanger and Corkum 2003). Thus, the shallow PZ might serve as a refuge for small round gobies offering increased protection against predation due to dense SAV. Additionally, more complex vegetated habitats might provide better feeding conditions with a higher availability of prey organisms for juvenile round gobies as high macroinvertebrate abundance and biomass, and especially mobile organisms, are usually associated with vegetation (Boström and Bonsdorff 1997; Christie et al. 2009; Henseler et al. 2019).

However, since habitat types examined in this study did not only differ concerning SAV density but also with regard to depth, the high occurrence of small round gobies cannot unambiguously be linked to the structural complexity of the habitats, as depth might also play a role in structuring the fish community. Studies have shown that juvenile fish abundances can be higher in shallow habitats compared with similarly complex, deeper areas, which is often explained by lower abundances of large predatory fish in shallow habitats and thus reduced predation risk for juveniles (Baker and Sheaves 2007; Ryer et al. 2010). Yet, this relation does not always apply, suggesting that juvenile abundance is not exclusively structured by vertical depth. In our study, it seems rather unlikely that effects of depth differences between habitats override effects of habitat complexity, especially as high fish abundances and low predation risk are generally associated with structurally more complex, vegetated habitats (Nagelkerken et al. 2001; Heck Jr. et al. 2003; La Mesa et al. 2011; Chacin and Stallings 2016; Reynolds et al. 2018). Furthermore, when conducting preliminary beach seine samplings in shallow areas of Greifswald Bay, round gobies were always present in vegetated areas, but never on bare sand (personal observation). Nevertheless, the depth gradient at the study site might have influenced round goby distribution additionally, promoting high abundances of small round gobies in the shallower habitat. Moreover, samples were only taken during daytime in our study. Therefore, future studies should investigate this aspect more closely by assessing round goby abundances in adjacent vegetated and non-vegetated habitats of the same depth and during different times of day (cf. Ray and Corkum 2001). Vegetated habitats might only serve as a refuge during daytime when small round gobies are susceptible to predation. However, round gobies might move into more open areas during the night with darkness potentially offering increased protection against predators. 
Higher abundances of juvenile round gobies in the $P Z$ could have implications for the native fish community in Greifswald Bay. These shallow vegetated areas serve as important spawning beds for spring-spawning Atlantic herring (Kanstinger et al. 2018), and round gobies smaller than $10 \mathrm{~cm}$ have been reported to feed on herring eggs in the field during spring (Wiegleb et al. 2018). Thus, large numbers of juvenile individuals could have a negative impact on herring recruitment. Furthermore, round goby can compete for habitat and food resources with native fish species (Hirsch et al. 2016). In our study, fish caught alongside round goby represented species commonly inhabiting the study area (Winkler and Thiel 1993). Gobies of the genus Pomatoschistus had a comparatively high occurrence in the samples (Supplementary Fig. S2), and, as benthic fish, they are likely to interact most with similarly sized round gobies due to competition. The local predatory fish community might also benefit from the presence of small round gobies, as various native species including perch and pikeperch feed on round goby (Oesterwind et al. 2017), which therefore are likely to become part of the local food web transferring additional energy to higher trophic levels (Johnson et al. 2005; Campbell et al. 2009).

\section{Diet composition of round goby}

Several benthic macroinvertebrate species were identified in the round goby stomachs, representing organisms that are commonly found in the study area (Jönsson et al. 1997; for a complete prey species list, cf. Table 1 in Oesterwind et al. 2017). Freely moving species, such as Idotea chelipes, gammarids and Hydrobia spp., as well as the bivalve Mytilus sp. are frequently associated with vegetated areas in Greifswald Bay, whereas chironomids, ostracods, Hediste diversicolor, Corophium spp. and the bivalves Cerastoderma spp., Limecola balthica, and Mya arenaria inhabit sandy to muddy sediments (Geisel and Meßner 1989; Günther 1998). Thus, the diet spectrum of round goby incorporated a broad variety of prey organisms from the local macroinvertebrate community.

Although round gobies from both $\mathrm{LC}_{1}$ and $\mathrm{LC}_{2}$ mainly fed on arthropods, we found a significant difference in diet composition between these length classes. Whereas copepods, ostracods and cladocerans were present in the diet of $\mathrm{LC}_{1}$ gobies, medium-sized gobies from $\mathrm{LC}_{2}$ increasingly fed on isopods, amphipods and gastropods. Round gobies from the two smaller length classes thus consumed different crustacean prey taxa indicating an ontogenetic diet shift from zooplanktonic organisms to larger crustaceans for round gobies at a size of about $50 \mathrm{~mm}$ TL. This is in line with other studies from the Baltic Sea (Rakauskas et al. 2008; Skabeikis and Lesutienè 2015; Ustups et al. 2016) and the Great Lakes (Cooper et al. 2009; Brush et al. 2012; Olson and Janssen 2017), which report a high proportion of copepods, cladocerans and ostracods in the diet of smaller individuals. An increasing importance of larger crustaceans with round goby size has also been found in other areas. However, besides amphipods, other crustacean taxa, such as mysids and decapods, are consumed by similar sized round gobies (Rakauskas et al. 2008; Skabeikis and Lesutienè 2015; Ustups et al. 2016). Hence, the overall ontogenetic diet trend seems to be similar for different invaded regions, but the specific diet composition (i.e. the prey taxa) might depend on the study area and, most likely, on which prey items are available in a specific environment. Contrary to the smaller length classes, large gobies from $\mathrm{LC}_{3}$ predominantly consumed polychaetes and bivalves (keeping in mind the small sample size and the absence of statistical analysis for $\mathrm{LC}_{3}$ ), which might confirm an ontogenetic diet shift with increasing molluscivory for our study area. A higher percentage of molluscs, especially bivalves, in the diet of larger round gobies is known from the Ponto-Caspian region (Svetovidov 1964; Pinchuk et al. 2003; Bogutskaya et al. 2004), as well as from multiple colonized areas, such as the Baltic Sea (Skora and Rzeznik 2001; Karlson et al. 2007), the Great Lakes (Johnson et al. 2005; Duncan et al. 2011) and river or canal systems (Brandner et al. 2013; Hempel et al. 2019). In the Baltic Sea, mainly Limecola balthica and Mytilus spp. are consumed, whereas dreissenid mussels constitute the main proportion of mollusc prey in the Great Lakes. In its native range, round gobies feed on a large number of mollusc species, amongst others, including Cerastoderma glaucum and Abra segmentum (Svetovidov 1964; Kvach and Zamorov 2001; Pinchuk et al. 2003; Bogutskaya et al. 2004). Similar to our findings, a higher contribution of annelids, including polychaetes, to the diet of larger round gobies has been documented in a brackish water canal and the southeastern Baltic Sea (Skabeikis and Lesutiene 2015; Hempel et al. 2019), although other studies found a declining importance of polychaetes with increasing goby size (Skora and Rzeznik 2001). Thus, our results show a certain accordance with other areas inhabited by this species concerning the diet spectrum of different length classes, though regional differences in diet composition exist, which are possibly linked to the prey availability in the respective environments. The distinct diet composition of differently sized individuals indicates that the impact of round gobies on native macroinvertebrate communities will depend on which round goby sizes prevail in a specific region. Although no fish eggs and larvae were found in the stomachs examined in this study, predation of round goby on the fry of resident species at the study site, such as Atlantic herring, cannot be excluded as it has been shown that small round gobies prey on herring eggs during springtime in Greifswald Bay (Wiegleb et al. 2018). Generally, round goby predation on eggs might be difficult to detect by means of stomach content analyses (Lutz et al. 2020). However, since the colonization of the area and the corresponding restructuring of the regional food web are still in 
progress, consequences for the ecosystem and fishing resources are not yet fully predictable (Campbell et al. 2009; Hempel et al. 2016).

Based on qualitative observations, the diet composition of round goby differed between the studied habitat types in autumn (in both October and November) within $\mathrm{LC}_{1}$. Specifically, the diet in the $P Z$ was most distinct from the other two habitats in both sampling months. Round gobies in the $P Z$ fed on a higher number of different prey taxa, which could be related to a higher species richness in this shallower vegetated habitat compared with the structurally less complex $Z Z$ and SZ. It has been shown that more complex, vegetated habitat types usually possess a different invertebrate community composition in addition to higher invertebrate species richness and diversity than non-vegetated areas (Boström and Bonsdorff 1997; Henseler et al. 2019). Accordingly, some organisms were exclusively found in round goby diet from the $P Z$, such as amphipods and isopods. These mobile crustaceans were potentially associated with SAV in the $P Z$. Crustaceans such as gammarids and Idotea chelipes inhabit vegetated areas in Greifswald Bay (Geisel and Meßner 1989; Günther 1998), and similar findings from the Gulf of Gdansk in the southeastern Baltic Sea show that the isopod Idotea balthica constitutes a high proportion of round goby diet in a macrophyte habitat (Skora and Rzeznik 2001). This might indicate a link between round goby diet and the prey availability in a specific environment with round gobies feeding on whichever prey taxa occur. It has been documented that round goby possesses an opportunistic feeding strategy and flexibly adapts its diet to seasonal changes in invertebrate community composition (Borza et al. 2009; Borcherding et al. 2013; Brandner et al. 2013). Thus, round goby might not have a preference for specific prey taxa but is instead able to consume a broad variety of different prey items as a generalist species (Raby et al. 2010; Brandner et al. 2013; Nurkse et al. 2016). In summary, our results on diet composition of round goby in different habitats might indicate an opportunistic feeding behaviour of this species, which represents a trait often expressed by invasive species. Opportunistic feeding might, in this respect, facilitate the colonization of different areas and therefore link to invasion success (Ribeiro et al. 2007; Rewicz et al. 2014; Pettitt-Wade et al. 2015; de Carvalho et al. 2019). However, our findings on habitat-dependent feeding of round goby have to be considered with caution keeping in mind that the results cannot be confirmed by statistical analysis, probably due to low sample sizes in the $Z Z$ and $S Z$ (number of gobies ranging between 3 and 11 in October and November). Moreover, no data on prey availability in the studied habitats was collected. To fully investigate opportunistic feeding of round gobies, it would be necessary to quantify invertebrate communities in multiple habitats and compare these to round goby diet composition, which was, however, not accomplished within our study.
Furthermore, future investigations should also include other habitat types in the study area, which could not be considered in this study, but might help to increase knowledge on the round goby's plasticity regarding habitat use and feeding behaviour.

\section{Conclusion}

Overall, our study suggests that shallower, more structured habitats serve as important areas for juvenile round gobies, as higher abundances were found in the shallow, densely vegetated habitats of the littoral zone compared with the deeper, less structured habitats at the study site. Diet composition of round goby differed between length classes. Whereas the smallest individuals $\left(\mathrm{LC}_{1}\right)$ mostly fed on zooplankton, including copepods, ostracods and cladocerans, medium-sized specimen $\left(\mathrm{LC}_{2}\right)$ increasingly consumed benthic crustaceans, such as amphipods and isopods, suggesting an ontogenetic diet shift regarding crustacean prey organisms. As commonly stated in literature, the proportion of molluscs increased in the diet of larger round gobies $\left(\mathrm{LC}_{3}\right)$. Furthermore, we offer indications for habitat-specific feeding of round goby within the smallest length class, which would conform to the generally suggested opportunistic feeding strategy for this species. Our findings shed light on the basic ecology of a widely spread invasive fish species in a quite recently, and therefore not yet extensively studied, colonized region, which could contribute to assessing its impact in non-native ecosystems and to the design of adequate management actions.

Acknowledgements We thank the Institute for Hydrobiology and Fisheries Science at the University of Hamburg for the loan of the boat "Belone", as well as M. Powilleit and A. Jetter for their support with invertebrate identification and C. Bock for her help with field work. We also want to thank $\mathrm{H}$. Winkler for his constructive and helpful comments on the manuscript.

Funding Open access funding was provided by Åbo Akademi University ( $\AA A U)$. This study was part of the BONUS Bio- $\mathrm{C}^{3}$ and INSPIRE projects (Art 185), funded jointly by the EU (Grant No. 03F0682B and 03F0681B) and through national funding by the German Federal Ministry of Education and Research (BMBF). $\mathrm{CH}$ was financed by the Åbo Akademi University doctoral network FunMarBio and by the MARmaED project, which has received funding from the European Union's Horizon 2020 research and innovation programme under the Marie Skłodowska-Curie grant agreement No. 675997. The results of this publication reflect only the author's view, and the Commission is not responsible for any use that may be made of the information it contains. $\mathrm{EB}$ and MCN acknowledge the Åbo Akademi University Foundation.

\section{Compliance with ethical standards}

Conflict of interest The authors declare that they have no conflict of interest. 
Ethical approval All applicable international, national, and/or institutional guidelines for the care and use of animals were followed by the authors.

Sampling and field studies All necessary permits for sampling and observational field studies have been obtained by the authors from the competent authorities and are mentioned in the acknowledgements, if applicable.

Data availability The datasets generated during and/or analysed during the current study are available from the corresponding author on request.

Authors' contributions Designed the field study: CH, PK, DO. Performed the field work and lab analysis: $\mathrm{CH}, \mathrm{PK}$, DO. Conducted the statistical analysis of the data: $\mathrm{CH}$. Wrote the manuscript: $\mathrm{CH}, \mathrm{PK}, \mathrm{EB}$, MCN, DO

Open Access This article is licensed under a Creative Commons Attribution 4.0 International License, which permits use, sharing, adaptation, distribution and reproduction in any medium or format, as long as you give appropriate credit to the original author(s) and the source, provide a link to the Creative Commons licence, and indicate if changes were made. The images or other third party material in this article are included in the article's Creative Commons licence, unless indicated otherwise in a credit line to the material. If material is not included in the article's Creative Commons licence and your intended use is not permitted by statutory regulation or exceeds the permitted use, you will need to obtain permission directly from the copyright holder. To view a copy of this licence, visit http://creativecommons.org/licenses/by/4.0/.

\section{References}

Almqvist G, Strandmark AK, Appelberg M (2010) Has the invasive round goby caused new links in Baltic food webs? Environ Biol Fish 89:79-93. https://doi.org/10.1007/s10641-010-9692-z

Baker R, Sheaves M (2007) Shallow-water refuge paradigm: conflicting evidence from tethering experiments in a tropical estuary. Mar Ecol Prog Ser 349:13-22. https://doi.org/10.3354/meps07102

Barton DR, Johnson RA, Campbell L et al (2005) Effects of round gobies (Neogobius menalostomus) on dreissenid mussels and other invertebrates in eastern Lake Erie, 2002-2004. J Great Lakes Res 31:252261. https://doi.org/10.1016/S0380-1330(05)70318-X

Bauer CR, Bobeldyk AM, Lamberti GA (2007) Predicting habitat use and trophic interactions of Eurasian ruffe, round gobies, and zebra mussels in nearshore areas of the Great Lakes. Biol Invasions 9: 667-678. https://doi.org/10.1007/s10530-006-9067-8

Bauer RK (2018) Oceanmap: a plotting toolbox for 2D oceanographic data. R package version 0.1.0. https://CRAN.R-project.org/ package $=$ oceanmap

Belanger RM, Corkum LD (2003) Susceptibility of tethered round gobies (Neogobius melanostomus) to predation in habitats with and without shelters. J Great Lakes Res 29:588-593. https://doi.org/10.1016/ S0380-1330(03)70462-6

Bivand R, Keitt T, Rowlingson B (2017) rgdal: bindings for the "geospatial" data abstraction library. R package version 1:2-16 https://CRAN.R-project.org/package=rgdal

Bogutskaya NG, Boldyrev VS, Naseka AM (2004) Neogobiin gobies (Teleostei: Gobiidae) in ecosystems of Eurasia and North American Great Lakes (in Russian). In: Alimov AF, Bogutskaja NG (eds) Biological invasions in aquatic and terrestrial ecosystems. KMK Scientific Press Ltd, Moscow - Saint Petersburg, pp 297-320
Borcherding J, Dolina M, Heermann L et al (2013) Feeding and niche differentiation in three invasive gobies in the Lower Rhine, Germany. Limnologica 43:49-58. https://doi.org/10.1016/j.limno. 2012.08.003

Borza P, Erős T, Oertel N (2009) Food resource partitioning between two invasive Gobiid species (Pisces, Gobiidae) in the littoral zone of the river Danube, Hungary. Int Rev Hydrobiol 94:609-621. https://doi. org/10.1002/iroh.200911134

Boström C, Bonsdorff E (1997) Community structure and spatial variation of benthic invertebrates associated with Zostera marina (L.) beds in the northern Baltic Sea. J Sea Res 37:153-166. https://doi. org/10.1016/S1385-1101(96)00007-X

Brandner J, Auerswald K, Cerwenka AF et al (2013) Comparative feeding ecology of invasive Ponto-Caspian gobies. Hydrobiologia 703: 113-131. https://doi.org/10.1007/s10750-012-1349-9

Brunsdon C, Chen H (2014) GISTools: some further GIS capabilities for R. R package version 0.7-4. https://CRAN.R-project.org/package= GISTools

Brush JM, Fisk AT, Hussey NE, Johnson TB (2012) Spatial and seasonal variability in the diet of round goby (Neogobius melanostomus): stable isotopes indicate that stomach contents overestimate the importance of dreissenids. Can J Fish Aquat Sci 69:573-586. https:// doi.org/10.1139/f2012-001

Campbell LM, Thacker R, Barton D et al (2009) Re-engineering the eastern Lake Erie littoral food web: the trophic function of nonindigenous Ponto-Caspian species. J Great Lakes Res 35:224-231. https://doi.org/10.1016/j.jglr.2009.02.002

Chacin DH, Stallings CD (2016) Disentangling fine- and broad- scale effects of habitat on predator-prey interactions. J Exp Mar Biol Ecol 483:10-19. https://doi.org/10.1016/j.jembe.2016.05.008

Christie H, Norderhaug KM, Fredriksen S (2009) Macrophytes as habitat for fauna. Mar Ecol Prog Ser 396:221-233. https://doi.org/10.3354/ meps08351

Cooper MJ, Ruetz CR III, Uzarski DG, Burton TM (2007) Distribution of round gobies in coastal areas of Lake Michigan: are wetlands resistant to invasion? J Great Lakes Res 33:303-313. https://doi.org/10. 3394/0380-1330(2007)33[303:DORGIC]2.0.CO;2

Cooper MJ, Ruetz CR III, Uzarski DG, Shafer BM (2009) Habitat use and diet of the round goby (Neogobius melanostomus) in coastal areas of Lake Michigan and Lake Huron. J Freshw Ecol 24:477488. https://doi.org/10.1080/02705060.2009.9664321

Coulter DP, Murry BA, Uzarski DG (2015) Relationships between habitat characteristics and round goby abundance in lakes Michigan and Huron. J Great Lakes Res 41:890-897. https://doi.org/10.1016/j. jglr.2015.06.001

de Carvalho DR, de Castro DMP, Callisto M et al (2019) Stable isotopes and stomach content analyses indicate omnivorous habits and opportunistic feeding behavior of an invasive fish. Aquat Ecol 53:365381. https://doi.org/10.1007/s10452-019-09695-3

Duncan JM, Marschner CA, González MJ (2011) Diet partitioning, habitat preferences and behavioral interactions between juvenile yellow perch and round goby in nearshore areas of Lake Erie. J Great Lakes Res 37:101-110. https://doi.org/10.1016/j.jglr.2010.11.015

Florin A-B, Hüssy K, Blass M et al (2018) How old are you-evaluation of age reading methods for the invasive round goby (Neogobius melanostomus, Pallas 1814). J Appl Ichthyol 34:653-658. https:// doi.org/10.1111/jai.13596

Fox J, Weisberg S (2011) An $\{\mathrm{R}\}$ companion to applied regression, Second edn. Sage, Thousand Oaks CA

Geisel T, Meßner U (1989) Flora und Fauna des Bodens im Greifswalder Bodden. In: Meer und Museum, Band 5. Der Greifswalder Bodden. Stiftung Deutsches Meeresmuseum, Stralsund, pp 44-51

Günther B (1998) Die Bedeutung des Makrozoobenthos für den Stoffumsatz im Sediment. Greifswalder Bodden und Oderästuar Austauschprozesse (GOAP). Report 13. Greifswalder Geographische Arbeiten 
Heck K Jr, Hays G, Orth R (2003) Critical evaluation of the nursery role hypothesis for seagrass meadows. Mar Ecol Prog Ser 253:123-136. https://doi.org/10.3354/meps253123

Hempel M, Magath V, Neukamm R, Thiel R (2019) Feeding ecology, growth and reproductive biology of round goby Neogobius melanostomus (Pallas, 1814) in the brackish Kiel Canal. Mar Biodivers 49:795-807. https://doi.org/10.1007/s12526-018-0854-0

Hempel M, Neukamm R, Thiel R (2016) Effects of introduced round goby (Neogobius melanostomus) on diet composition and growth of zander (Sander lucioperca), a main predator in European brackish waters. Aquat Invasions 11:167-178. https://doi.org/10.3391/ai. 2016.11.2.06

Henseler C, Nordström MC, Törnroos A et al (2019) Coastal habitats and their importance for the diversity of benthic communities: a speciesand trait-based approach. Estuar Coast Shelf Sci 226:106272. https://doi.org/10.1016/j.ecss.2019.106272

Herlevi H, Aarnio K, Puntila-Dodd R, Bonsdorff E (2018) The food web positioning and trophic niche of the non-indigenous round goby: a comparison between two Baltic Sea populations. Hydrobiologia 822:111-128. https://doi.org/10.1007/s10750-018-3667-z

Hijmans RJ (2017) Raster: geographic data analysis and modeling. R package version 2:6-7 https://CRAN.R-project.org/package=raster

Hirsch PE, N'Guyen A, Adrian-Kalchhauser I, Burkhardt-Holm P (2016) What do we really know about the impacts of one of the 100 worst invaders in Europe? A reality check. Ambio 45:267-279. https://doi. org/10.1007/s13280-015-0718-9

Houghton CJ, Janssen J (2015) Changes in age-0 yellow perch habitat and prey selection across a round goby invasion front. J Great Lakes Res 41:210-216. https://doi.org/10.1016/j.jglr.2015.10.004

Janssen J, Jude DJ (2001) Recruitment failure of mottled sculpin Cottus bairdi in Calumet Harbor, southern Lake Michigan, induced by the newly introduced round goby Neogobius melanostomus. J Great Lakes Res 27:319-328. https://doi.org/10.1016/S0380-1330(01) 70647-8

Johnson TB, Bunnell DB, Knight CT (2005) A potential new energy pathway in Central Lake Erie: the round goby connection. J Great Lakes Res 31:238-251

Jönsson N, Busch A, Lorenz T, Korth B (1997) Struktur und Funktion von Boddenlebensgemeinschaften im Ergebnis von Austausch- und Vermischungsprozessen. Greifswalder Bodden und Oderästuar Austauschprozesse (GOAP). Final Report (12) 1997. Greifswalder Geographische Arbeiten

Jůza T, Blabolil P, Baran R et al (2018) Collapse of the native ruffe (Gymnocephalus cernua) population in the Biesbosch lakes (the Netherlands) owing to round goby (Neogobius melanostomus) invasion. Biol Invasions 20:1523-1535. https://doi.org/10.1007/ s10530-017-1644-5

Kanstinger P, Beher J, Grenzdörffer G et al (2018) What is left? Macrophyte meadows and Atlantic herring (Clupea harengus) spawning sites in the Greifswalder Bodden, Baltic Sea. Estuar Coast Shelf Sci 201:72-81. https://doi.org/10.1016/j.ecss.2016.03. 004

Karlson AML, Almqvist G, Skóra KE, Appelberg M (2007) Indications of competition between non-indigenous round goby and native flounder in the Baltic Sea. ICES J Mar Sci 64:479-486. https:// doi.org/10.1093/icesjms/fs1049

Kipp R, Hébert I, Lacharité M, Ricciardi A (2012) Impacts of predation by the Eurasian round goby (Neogobius melanostomus) on molluscs in the upper St. Lawrence River J Great Lakes Res 38:78-89. https:// doi.org/10.1016/j.jglr.2011.11.012

Kipp R, Ricciardi A (2012) Impacts of the Eurasian round goby (Neogobius melanostomus) on benthic communities in the upper St. Lawrence River. Can J Fish Aquat Sci 69:469-486. https://doi. org/10.1139/f2011-139

Kornis MS, Mercado-Silva N, Vander Zanden MJ (2012) Twenty years of invasion: a review of round goby Neogobius melanostomus biology, spread and ecological implications. J Fish Biol 80:235285. https://doi.org/10.1111/j.1095-8649.2011.03157.x

Kotta J, Nurkse K, Puntila R, Ojaveer H (2016) Shipping and natural environmental conditions determine the distribution of the invasive non-indigenous round goby Neogobius melanostomus in a regional sea. Estuar Coast Shelf Sci 169:15-24. https://doi.org/10.1016/j. ecss.2015.11.029

Kvach Y, Zamorov V (2001) Feeding preferences of the round goby Neogobius melanostomus and mushroom goby Neogobius cephalarges in the Odessa Bay. Oceanol Stud 30:91-101

La Mesa G, Molinari A, Gambaccini S, Tunesi L (2011) Spatial pattern of coastal fish assemblages in different habitats in North-western Mediterranean. Mar Ecol 32:104-114. https://doi.org/10.1111/j. 1439-0485.2010.00404.x

Lederer A, Massart J, Janssen J (2006) Impact of round gobies (Neogobius melanostomus) on dreissenids (Dreissena polymorpha and Dreissena bugensis) and the associated macroinvertebrate community across an invasion front. J Great Lakes Res 32:1-10. https://doi.org/10.3394/0380-1330(2006)32[1: IORGNM]2.0.CO;2

Leppäkoski E, Olenin S (2000) Non-native species and rates of spread: lessons from the brackish Baltic Sea. Biol Invasions 2:151-163

Lutz E, Hirsch PE, Bussmann K et al (2020) Predation on native fish eggs by invasive round goby revealed by species-specific gut content DNA analyses. Aquatic Conserv: Mar Freshw Ecosyst. 2020:112. https://doi.org/10.1002/aqc.3409

Moll D, Kotterba P, von Nordheim L, Polte P (2018) Storm-induced Atlantic herring (Clupea harengus) egg mortality in Baltic Sea inshore spawning areas. Estuar Coasts 41:1-12. https://doi.org/10. 1007/s12237-017-0259-5

Moran EA, Simon TP (2013) Size, relative abundance, and catch-perunit-effort of round goby, Neogobius melanostomus, in anthropogenically modified and natural habitats in the western basin of Lake Erie. J Appl Ichthyol 29:1134-1138. https://doi.org/10.1111/jai. 12211

Nagelkerken I, Kleijnen S, Klop T et al (2001) Dependence of Caribbean reef fishes on mangroves and seagrass beds as nursery habitats: a comparison of fish faunas between bays with and without mangroves/seagrass beds. Mar Ecol Prog Ser 214:225-235. https://doi.org/10.3354/meps214225

Nurkse K, Kotta J, Orav-Kotta H, Ojaveer H (2016) A successful nonnative predator, round goby, in the Baltic Sea: generalist feeding strategy, diverse diet and high prey consumption. Hydrobiologia 777:271-281. https://doi.org/10.1007/s10750-016-2795-6

Oesterwind D, Bock C, Förster A et al (2017) Predator and prey: the role of the round goby Neogobius melanostomus in the western Baltic. Mar Biol Res 13:188-197. https://doi.org/10.1080/17451000.2016. 1241412

Oksanen J, Blanchet FG, Friendly M et al (2018) Vegan: community ecology package. $\mathrm{R}$ package version $2: 4-6$

Olson DS, Janssen J (2017) Early feeding of round goby (Neogobius melanostomus) fry. J Great Lakes Res 43:728-736. https://doi.org/ 10.1016/j.jglr.2017.04.006

Pettitt-Wade H, Wellband KW, Heath DD, Fisk AT (2015) Niche plasticity in invasive fishes in the Great Lakes. Biol Invasions 17:25652580. https://doi.org/10.1007/s10530-015-0894-3

Pinchuk V, Vasil'eva E, Vasil'ev V, Miller P (2003) Neogobius melanostomus (Pallas, 1814). In: Miller PJ (ed) The freshwater fishes of Europe, volume 8, part II: Gobiidae 2. Aula-Verlag, Wiebelsheim

R Core Team (2019) R: A language and environment for statistical computing. R Foundation for Statistical Computing, Vienna, Austria. URL https://www.R-project.org/

Raby GD, Gutowsky LFG, Fox MG (2010) Diet composition and consumption rate in round goby (Neogobius melanostomus) in its 
expansion phase in the Trent River, Ontario. Environ Biol Fish 89: 143-150. https://doi.org/10.1007/s10641-010-9705-y

Rakauskas V, Bacevičius E, Pūtys Ž et al (2008) Expansion, feeding and parasites of the round goby, Neogobius melanostomus (Pallas, 1811), a recent invader in the Curonian lagoon, Lithuania. Acta Zool Litu 18:180-190. https://doi.org/10.2478/v10043-008-0030-z

Ramler D, Keckeis H (2020) Effects of hydraulic engineering restoration measures on invasive gobies in a large river (Danube, Austria). Biol Invasions 22:437-453. https://doi.org/10.1007/s10530-019-02101-x

Ray WJ, Corkum LD (2001) Habitat and site affinity of the round goby. J Great Lakes Res 27:329-334. https://doi.org/10.1016/S03801330(01)70648-X

Reinicke R (1989) Der Greifswalder Bodden - geographischgeologischer Überblick, Morphogenese und Küstendynamik. In: Meer und Museum, Band 5. Der Greifswalder Bodden. Stiftung Deutsches Meeresmuseum, Stralsund, pp 3-9

Rewicz T, Grabowski M, MacNeil C, Bącela-Spychalska K (2014) The profile of a 'perfect' invader - the case of killer shrimp, Dikerogammarus villosus. Aquat Invasions 9:267-288. https://doi. org/10.3391/ai.2014.9.3.04

Reynolds PL, Stachowicz JJ, Hovel K et al (2018) Latitude, temperature, and habitat complexity predict predation pressure in eelgrass beds across the Northern Hemisphere. Ecology 99:29-35. https://doi.org/ 10.1002/ecy.2064

Ribeiro F, Orjuela RL, Magalhães MF, Collares-Pereira MJ (2007) Variability in feeding ecology of a South American cichlid: a reason for successful invasion in Mediterranean-type rivers? Ecol Freshw Fish 16:559-569. https://doi.org/10.1111/j.1600-0633.2007.00252.

Ryer C, Laurel B, Stoner A (2010) Testing the shallow water refuge hypothesis in flatfish nurseries. Mar Ecol Prog Ser 415:275-282. https://doi.org/10.3354/meps08732

Sapota M (2004) The round goby (Neogobius melanostomus) in the Gulf of Gdańsk - a species introduction into the Baltic Sea. Hydrobiologia 514:219-224

Sapota M, Skóra K (2005) Spread of alien (non-indigenous) fish species Neogobius melanostomus in the Gulf of Gdańsk (south Baltic). Biol Invasions 7:157-164. https://doi.org/10.1007/s10530-004-9035-0

Savino JF, Stein RA (1982) Predator-prey interaction between largemouth bass and bluegills as influenced by simulated, submersed vegetation. Trans Am Fish Soc 111:255-266. https://doi. org/10.1577/1548-8659(1982)111<255:PIBLBA >2.0.CO;2

Skabeikis A, Lesutienè J (2015) Feeding activity and diet composition of round goby (Neogobius melanostomus, Pallas 1814) in the coastal waters of SE Baltic Sea. Oceanol Hydrobiol Stud 44:508-519. https://doi.org/10.1515/ohs-2015-0048

Skabeikis A, Morkūnė R, Bacevičius E et al (2019) Effect of round goby (Neogobius melanostomus) invasion on blue mussel (Mytilus edulis trossulus) population and winter diet of the long-tailed duck
(Clangula hyemalis). Biol Invasions 21:911-923. https://doi.org/ 10.1007/s10530-018-1869-y

Skora KE, Rzeznik J (2001) Observations on diet composition of Neogobius melanostomus Pallas 1811 (Gobiidae, Pisces) in the Gulf of Gdansk (Baltic Sea). J Great Lakes Res 27:290-299. https://doi.org/10.1016/S0380-1330(01)70644-2

Skóra KE, Stolarski J (1993) New fish species in the Gulf of Gdańsk, Neogobius sp. [cf. Neogobius melanostomus (Pallas 1811)]. Bull Sea fish institute, Gdynia 1:83

Steinhart GB, Marschall EA, Stein RA (2004) Round goby predation on smallmouth bass offspring in nests during simulated catch-andrelease angling. Trans Am Fish Soc 133:121-131. https://doi.org/ 10.1577/T03-020

Stigge H-J (1989) Der Wasserkörper Bodden und seine Hydrodynamik. In: Meer und Museum, Band 5. Der Greifswalder Bodden. Stiftung Deutsches Meeresmuseum, Stralsund, pp 10-14

Svetovidov AN (1964) Gobius melanostomus Pallas. In: Ryby tshernogo morja ("fishes of the Black Sea", in Russian). Moscow - Leningrad, pp 435-440

Ustups D, Bergström U, Florin AB et al (2016) Diet overlap between juvenile flatfish and the invasive round goby in the central Baltic Sea. J Sea Res 107:121-129. https://doi.org/10.1016/j.seares.2015. 06.021

Vašek M, Všetičková L, Roche K, Jurajda P (2014) Diet of two invading gobiid species (Proterorhinus semilunaris and Neogobius melanostomus) during the breeding and hatching season: no field evidence of extensive predation on fish eggs and fry. Limnologica 46:31-36. https://doi.org/10.1016/j.limno.2013.11.003

Venables WN, Ripley BD (2002) Modern applied statistics with S, Fourth edn. Springer, New York ISBN 0-387-95457-0

Wiegleb J, Kotterba P, Hammer C, Oesterwind D (2018) Predation of the round goby (Neogobius melanostomus Pallas, 1814) on Atlantic herring eggs in the Western Baltic Sea. Mar Biol Res 14:9891003. https://doi.org/10.1080/17451000.2019.1577977

Winkler HM (2006) Die Fischfauna der südlichen Ostsee, Bemerkungen zum gegenwärtigen Kenntnisstand. Meeresangler-Magazin 16:1718

Winkler HM (1989) Fische und Fangerträge im Greifswalder Bodden. In: Meer und Museum, Band 5. Der Greifswalder Bodden. Stiftung Deutsches Meeresmuseum, Stralsund, pp 52-58

Winkler HM, Thiel R (1993) Beobachtungen zum aktuellen Vorkommen wenig beachteter Kleinfischarten an der Ostseeküste Mecklenburgs und Vorpommerns (Nordostdeutschland). Rostocker Meeresbiologische Beiträge 1:95-104

Publisher's note Springer Nature remains neutral with regard to jurisdictional claims in published maps and institutional affiliations. 